\title{
A Few Guidelines for a Good Usage of PLM Software
}

\author{
Mickaël David \\ LEMNA, IEMN-IAE, University of Nantes, France \\ mickael.david@univ-nantes.fr
}

\begin{abstract}
Softwares providers offer PLM solutions to support the homonym organizational approach, especially during New Product Development (NPD) process. However these tools are not a panacea. This communication takes its theoretical and methodological foundations in management science. We seek to understand how managers can influence the users so they make a good use of their PLM tool. We analyze the case of a car manufacturer that has purchased a PLM software eight years ago. Our qualitative approach has allowed us to highlighting the importance of managerial action and regulation for an efficient use of PLM tools. On a theoretical level, we use the PLM features in line with Grieves to determine the informational integration effectiveness permitted by the tool. We propose some extensions to the sociomaterial typology of agencies recognized in Information Systems literature. Finally, we propose some managerial guidelines for a good use of PLM tools.
\end{abstract}

Keywords: PLM Tools, NPD Process, Informational Integration, Agency, Rules of use.

\section{Introduction}

Many industrial companies have to produce more and more complex goods, while optimizing development costs and reducing time to market [1]. A major concern in this sector is being able to handle the various facets of a product (manufacturing, logistics, recycling...) in a comprehensive manner as soon as its design phase. However, the New Product Development (NPD) process is distributed among different organizational functions, and regularly inter-organizational [2]. Informational integration including sharing of updated documents is thus critique.

IT vendors offer packaged Product Lifecycle Management (PLM) solutions to meet this challenge [3]. The Literature recognizes three functional subsystems within these solutions: $1^{\circ}$ ) Organizational Memory System (OMS) with storage, classification and research features; $2^{\circ}$ ) Project and Resources Management System (PRMS), with workflow, monitoring and milestones features, and $3^{\circ}$ ) Collaborative Work System (CWS), with viewer features and management of files by their status [4], [5].

However these softwares sold in the market are not a panacea, their potential must be activated [6]. In management science, many researchers consider the organizational performance as an emergent, technical and social, construction [7]. In this communication, we seek to understand the construction of a performing use of 
the PLM softwares (i.e. here, a use permitting to improve the informational integration of NPD process). To do this, we have to identify the different causes enacting the idiosyncratic usage of the PLM software in an organization (see 3.1). We are not trying to determine what a good tool is but what a good use of this PLM tool is. Finally, we wish to be able to propose guidelines for a good use of PLM tools.

\section{State-of-the-Art}

The potential of these complex softwares must be activated during the implementation project. A "fit" between the users' practices (and others organizational specificities) and the IT solution must be created [8], [9]. However, a perfect fit seems impossible to obtain. The user's practices are too different and conflicting between them and with the organizational interest. This irreducible "misfit" is called "imposition"[8].

This potential of the software must be also activated by a good use of this solution. The term "infusion" of the technology is generally used to denote the complete appropriation of the tool spirit by users [10], which leads them to propose new developments of the solution or new virtuous uses of the existing solution [6]. A collective appropriation of the software (i.e the users' capacity to effectively use the solution's functionalities when it's necessary, and only when it's useful) is an important asset for an organization [5]. This appropriation need to be managed [11]. In this vein, workaround phenomena and resistance to use the tool are not necessary blamed. They can result from a second type of misfit called "deficiency"[8]. These phenomena can be the premise of the invention by users of new virtuous uses which are not foreseen by the solution designers [12], [13].

\section{Construction of Our Analytical Model}

Our analytical model is composed of a typology of causes of the IT use (independent variables) and of an informational integration model (dependent variable).

\subsection{The Causes of the Idiosyncratic Use of a PLM Tool}

We mobilize the concept of agency from the structurationist paradigm as it has been regularly used to answer this issue of the idiosyncratic use of PLM tools [7], [14]. Agency is conceptualized as a spatiotemporally located expression of a material or social structure influencing determination of actual action, in this case the use of the tool. Leonardi [14] makes a distinction between material agency and human agency. We separate the individual form of human agency and its organizational form represented by prescribed or emergent collective rules of use (Fig. 2).

We make again two distinctions in order to refine our analytical model: first, on the subject of these organizational rules between NPD process and PLM tool use; second, between intrinsic material agency (resulting from the basic structure of the tool) and extrinsic material agency (resulting from tool parameter settings wanted by the 
organization, and therefore which is a transfiguration of an organizational agency to a material agency).

Regulations are then captured by the organizational agency (NDP or PLM) and by the extrinsic material agency of the PLM tool. The intrinsic material agency and the individual agency allow us to put into perspective the need of managerial rules (by increasing it or decreasing it).

\subsection{Informational Integration Per Se}

Informational integration is often inferred from consequences presumed to cause (including coordination [15]), but it is rarely grasping per se [16]. Inspired by the characteristics of PLM tool, Grieves proposes six characteristics of product information integration: correspondence, singularity, traceability, differentiated availability, cohesion of representations and reflexivity [17]. These characteristics are consistent with the four phases of organizational memory generally used in the literature [18] as well as with the Patnayakuni, Ruppel et Rai's model of informational integration [16]. However, the characteristics of PLM tool have two advantages over the current informational integration model: the consideration of the acquisition phase and the consideration of the notion of parsimony by the differentiated availability of items (Fig. 1).

\begin{tabular}{|c|c|c|}
\hline $\begin{array}{l}\text { CHARACTERISTICS OF PLM } \\
\text { (Grieves 2006) }\end{array}$ & $\begin{array}{l}\text { ORGANIZATIONAL MEMORY } \\
\text { (Walsh and Ungson } \\
\text { 1991) }\end{array}$ & $\begin{array}{c}\text { INFORMATIONAL INTEGRATION } \\
\text { MODEL } \\
\text { (Patnayakuni, Ruppel } \\
\text { and Rai 2006) }\end{array}$ \\
\hline CORRESPONDENCE & \multirow{2}{*}{ ACQUISITION } & \multirow{2}{*}{ N/A } \\
\hline SINGULARITY & & \\
\hline TRACEABILITY & STORAGE & EASY ACCESSIBILITY \\
\hline N/A & \multirow{3}{*}{ DIFFUSION } & INFORMATION PORTABILITY \\
\hline DIFFERENTIATED AVAILABILITY & & N/A \\
\hline $\begin{array}{c}\text { COHESION OF } \\
\text { REPRESENTATIONS }\end{array}$ & & $\begin{array}{l}\text { NO LOSS OF SEMANTIC } \\
\text { INFORMATION }\end{array}$ \\
\hline REFLECTIVITY & USE & $\begin{array}{l}\text { COMMUNICATION OF } \\
\text { MODIFICATIONS }\end{array}$ \\
\hline
\end{tabular}

Fig. 1. Comparison of informational integration models (adapted from references)

- The information acquisition must be comprehensive. The correspondence ${ }^{* 1}$ is required between the information richness contained in PLM tool and the complexity of reality. The information acquisition must also be non-redundant. A singularity* of objects for the same information facilitates their updating.

- The information storing represents an informational integration with past tasks/phases. This integration is characterized by an easy accessibility to historical data design\#, especially permitted by their traceability*.

\footnotetext{
1 * Items from Grieves [17], \# items from Patnayakuni, Ruppel et Rai [16].
} 
- The information diffusion must be efficient. Under condition of information portability\#, only the information needed must be presented at user, and in a relevant way. The availability is differentiated* by the user's interest. However, this personalization should not prevent the cohesion of virtual representations* and it should preserve the coherence of the logical model\#. The aim is mutual understanding of different trades without loss of semantic information\#.

- Finally, informational integration implies that any change to the environment captured by the system is communicated\# in order to produce the necessary consequences about its use (the reflectivity* in the Grieves' terminology).

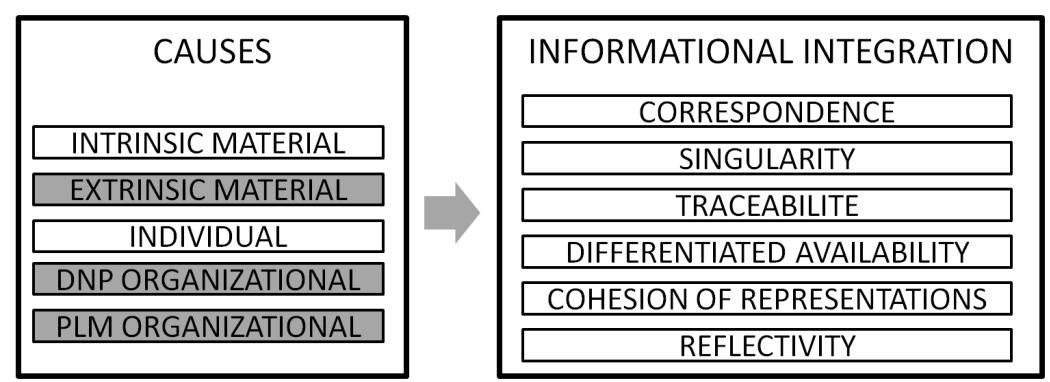

Fig. 2. Our analytical model (the three shaded variables are the managerial variables)

\section{The Results of the Case Studied}

The case is a car manufacturer SME that designs, manufactures and assembles kits. The design and methods office is divided into four products families. There are forty PLM tool users; half of them work in the design and methods office.

The solution has been implemented between 2002 and 2004 by a phased deployment is Smarteam of Dassault Systemes. The available PLM functionalities are limited compared to functionalities offered on the market (no workflow, no project monitoring). In addition, the junction with the enterprise system is not carried out. Then, the PLM tool is used as an electronic documents management server offering some collaborative features. The results will be presented successively depending on the informational integration model (Fig. 2).

\subsection{Information Acquisition}

The correspondence (or completeness) is examined in width and breadth.

The principle of formalization is inherent to design office work; the individual agency and the NPD organizational agency are congruent. The PLM functionalities (interfaced with CAD software) lead Smarteam to almost exclusively support technical information on product, such as CAD or DXF (Drawing eXchange Format) files, plans, test and accreditation reports; an intrinsic material agency supports the correspondence of this information with reality. 
With regards to the information depth, the expected level of product detail by major car manufacturers is greater than that expected by this enterprise for its product on own-brand. Major car manufacturers require their parts are fully defined. However, a part's product on own-brand is described in order to provide ease of assembly. Thus there is a NDP organizational agency on a more or less important detail degree of CAD files.

These agencies coincide for that product information has a good correspondence with reality, both in width and breadth (less for the products on own-brand).

The information singularity is in particular obtained by the absence of multiple individual agencies. There is only one designer per team because the design and methods office is divided into products families (NPD organizational agency). In these conditions the PLM tool becomes the single source of product information without difficulties (as wanted by the organization) through its shared server and its indexed incrementing of files (intrinsic material agency). However, interoperability problems sometimes require records in various formats and/or on different servers (adverse intrinsic material agency).

The acquisition phase of product information meets the correspondence criterion and meets relatively well the singularity criterion. This effectiveness is enabled by the overall convergence of various organizational, material and individual agencies. However, the information singularity appears to be the result both of the reduced structure of the organization and of the intrinsic properties of the tool.

\subsection{Information Storage}

The documentary retrieval and the traceability are only partially effective. The documentary ontology of PLM tool (extrinsic material agency) supports generally the various attributes of product information. The users dispose of search unique keys as plan number for example.

However, designers are allowed to create their own folder in the tool directory tree (no extrinsic material agency). Thus, designers are free to organize the project folder as they want, to store anything they want in this folder, but especially they are free to name their files the way they want (individual agency/absence of PLM organizational agency). Eight years after the implementation of PLM tool, this absence of standardization of PLM use rules leads to time-consuming consequences. The designers have difficulty to retrieval a document if they are not the creator of it or if the document is "stored" in a folder which they are not accustomed. The peripheral users, such as those of manufacturing workshop or warehouse, use only the search keys and refuse a visual search in the directory tree without being leading by a designer by phone. Documents such as procedures have not attributes offering specific search keys. They are therefore particularly susceptible to problems resulting from the weak structuring of the directory tree. In addition, the NDP organizational agency promotes an accounting perspective on the project perimeter: a project is an 
annual expenditure commitment. Then there are as many folders as calendar years for a same technical project. This causes an expansion of the directory tree increasing the difficulty of visual search.

Storage and retrieval are therefore only partially effective (because it is sometimes laborious) despite the various features offered by PLM tool (intrinsic material agencies). It seems that the company has relied too much on the intrinsic properties of the tool. Despite the small size of the company, several users work on the same project and must access to the same documents. This common tool requires common rules of use (i.e. standards that counteract the multiplicity of individual patterns of use) especially in structuring of directory tree and in description of items.

\subsection{Information Diffusion}

Differentiated availability is only partially effective too. We analyze it with two points of view: static and dynamic.

Only documents having the last index are available for manufacturing workshop. However, despite the structuring of organization by products families, everyone has access to the folders of others products families. User profiles are not fully utilized (partial extrinsic material agency). In a dynamic point of view, the PLM tool does not contain workflow functionality (not intrinsic material agency). The information transfer by PLM tool is mainly pulled by manufacturing workshop or quality department. The designer (individual agency) is the pilot of the design and he pushes the information when he needs it, especially for prototyping. A procedure of electronic diffusion of technical notes via email (with a link to the document in Smarteam) has recently been implemented (PLM organizational agency). For some, the e-mail inbox provides a more efficient search engine than the one of Smarteam.

The partial formalization of the availability is based on the individual responsibility. In the retrieval case, the users have to differentiate useful information and in the filing case, they have to find the appropriate location storage of the document.

Cohesion of virtual representations (not mental) calls several objects of representation: the directory tree, the product geometry or the technical domain of product. The directory tree of a project is the same regardless of the user, so there are no distinct representations. However, we have seen, the directory tree is subject to the accountant constraint (adverse PLM organizational agency). Then the geometric vision of object in 2D (plan) is automatically generated from the CAD file (favorable intrinsic material agency). Finally, the electrical design is not integrated in mechanical CAD files because the CAD softwares (respectively Electra and Catia) are not interfaced (adverse intrinsic material agency). Due to the weak coupling of these two technical areas, the electrical design is realized according to the CAD file after mechanical design (adverse NPD organizational agency).

In information diffusion phase, the criterions of differentiated availability and of representations cohesion are only partially effective. Differentiated availability is only 
permitted by individual efforts and the pressure exerted by individuals to build better practices of PLM use. Regarding to cohesion of representations, only one between the plan and the CAD file seems to be sought by the organization.

\subsection{Information Use}

The criterion of information reflectivity translates into an automatic mechanism by the tool: an alert for updating of all products using a part/item which has just been modified (intrinsic material agency). This constraint of tool is not always respected because the added value of the operation is too weak compared to the time required to do it. This is legitimized by the collective criterion of weak impact on the product manufacturing. A NPD organizational agency counteracts the intrinsic material agency for time consuming tasks. Products having a long life-series have therefore a large number of inconsistency markers between the different versions of the parts and assemblies. In addition, the absence of intrinsic material agency regarding the technical integration of PLM tool with ERP tool does not permit to draw all consequences in terms of use cases and nomenclatures.

\subsection{Summary of the Results}

The figure 3 summarizes the results.

- The intrinsic material agency - the inherent properties of the tool - contributes to the effectiveness of informational integration in its various phases. However in this case, this contribution is lower on the last phases because there is neither workflow nor integration of CAD softwares and nor integration with ERP.

- The individual agency - the will of the individuals - has an ambivalent contribution: it generates a heterogeneity of practices (singularity, storage and retrieval), but it is also at the initiative of adaptive and palliative behaviors to functional deficiencies of the tool (storage, search and retrieval, differentiated availability).

- The extrinsic material agency - the parameter settings of the tool - does not seem necessary for the acquisition or use phases. However, it is necessary to optimizing the directory tree, the ontological structure of the database and the differentiated access to information by the individuals' digital profile.

- The PLM organizational agency - the rules of PLM tool use - is important for enforcing shared use practices of the tool (singularity), especially for imposing the filling of attributes and naming files standards and standards of structuring of directory tree (storage and documentary retrieval).

- The NPD organizational agency - the rules related to the NPD process - defines the degree of correspondence and the updating degree of parts (reflectivity). It regulates the information needing by structuring the project teams (singularity) and it defines the scope of project and related product information (storage and documentary retrieval). 


\begin{tabular}{|c|c|c|c|c|c|c|}
\hline & \multicolumn{2}{|c|}{ Acquisition } & \multirow{2}{*}{$\begin{array}{c}\text { Storage } \\
\text { Traçability } \\
\text { and } \\
\text { Retrieval } \\
\end{array}$} & \multicolumn{2}{|c|}{ Diffusion } & \multirow{2}{*}{$\begin{array}{c}\text { Use } \\
\text { Reflectivity }\end{array}$} \\
\hline & Correspondence & Singularity & & $\begin{array}{c}\text { Availability } \\
\text { discerned }\end{array}$ & $\begin{array}{c}\text { Representations } \\
\text { cohesion }\end{array}$ & \\
\hline $\begin{array}{l}\text { Intrinsic } \\
\text { Material } \\
\text { Agency } \\
\end{array}$ & 4 & & & & 5 & \\
\hline $\begin{array}{l}\text { Individual } \\
\text { Agency }\end{array}$ & $\widehat{1}$ & & & & & \\
\hline $\begin{array}{c}\text { Extrinsic } \\
\text { Material } \\
\text { Agency }\end{array}$ & & & & & & \\
\hline $\begin{array}{c}\text { PLM } \\
\text { Organizational } \\
\text { Agency }\end{array}$ & & & & & & \\
\hline $\begin{array}{c}\text { NPD } \\
\text { Organizational } \\
\text { Agency } \\
\end{array}$ & & & & & 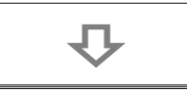 & \\
\hline Effectiveness & $\mathbb{3}$ & $\mathfrak{3}$ & $\mathfrak{3}$ & $\llbracket$ & $\nwarrow$ & $\sqrt{3}$ \\
\hline
\end{tabular}

The three shaded boxes correspond to the measurement of regulations.
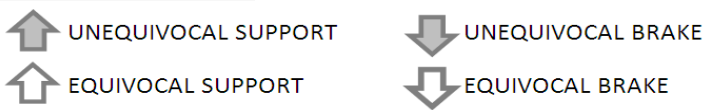

\STRONG EFFECTIVENESS

\& WEAK EFFECTIVENESS

Fig. 3. Summary of the results

\section{Discussion}

After eight years of using the solution, information retrieval is more difficult. Informational saturation is a risk in the medium term. The company has opted for a weak formalization and standardization of PLM uses to increase the chances of acceptance of tool by users. The daily users have integrated the underlying logic of the tool and they have gradually created virtuous uses. For instance, they use this for constituting a catalog of standard parts or for sharing documents formalizing information on the project progress or on manufacturing workshop's constraints.

It is necessary to exceed the ambivalent character of the regulation by distinguishing between aspects of the usage of PLM software that require strict rules of use and those for which users' leeway is preferable in order to activate the potential of PLM software. The leeway given to users to create, to organize their folders and to store any document (if the required documents are present) into the PLM tool seems to be a good management practice, especially for appropriation of the tool by users. However, this implies strict rules for naming files and filling of their attributes in order that retrieval functionalities can effectively operate. The consequences are that is also necessary to ensure the adaptation of the ontological structure of the tool to new uses and to formalize tasks for ensuring the maintenance of the information content of the tool.

\section{Conclusion}

This communication takes its theoretical and methodological foundations in management science. By a qualitative approach, we study how users are influenced when they use the 
tool and what is the performance of this use in terms of informational integration. We have developed a model to assess the informational integration; it must also be validated by more systematic studies. Although they must to check them on other cases, this case study allows us to consider a few managerial guidelines for optimize the use of the solution.

- The technical integration of the PLM software with CAD and ERP softwares must be wanted because it is necessary for enabled various functionalities of PLM software.

- The modeling of (changing) practices and informational environment of the NDP process should be accurate, inserted and updated in parameter setting in the tool.

- Some usage rules must be put in place (the filling of attributes, the naming of files and the structuring of the directory tree). It is important to not formalize the contents of the tool in order to let users set up their own personal space and uses it to develop virtuous usages of the tool.

- These tools are not able to forget; it's important to formalize tasks for ensuring the maintenance of the information contained in the tool.

\section{References}

[1] Hatchuel, A., Weil, B.: Design-oriented organizations. In: 6th International Product Development Management Conference (1999)

[2] Merminod, V., Rowe, F.: How does PLM technology support knowledge transfer and translation in new product development? Transparency and Boundary Spanners in an International Context. Information and Organization 22(4), 295-322 (2012)

[3] Ameri, F., Dutta, D.: Product lifecycle management: closing the knowledge loops. Computer-Aided Design \& Applications 2(5), 577-590 (2005)

[4] Nambisan, S.: Information Systems as a Reference Discipline for New Product Development. MIS Quarterly 27(1), 1-18 (2003)

[5] Pavlou, P.A., El Sawy, O.A.: From IT leveraging competence to competitive advantage in turbulent environments: The case of new product development. Information Systems Research 17(3), 198-227 (2006)

[6] Leonardi, P.M.: Activating the Informational Capabilities of Information Technology for Organizational Change. Organization Science 18(5), 813-831 (2007)

[7] Desanctis, G., Poole, M.S.: Capturing the Complexity in Advanced Technology Use: Adaptive Structuration Theory. Organization Science 5(2), 121-148 (1994)

[8] Strong, D.M., Volkoff, O.: Understanding Organization-Enterprise System Fit: A Path To Theorizing the Information Technology Artifact. MIS Quarterly 34(4), 731-756 (2010)

[9] Garetti, M., Terzi, S., Bertacci, N., Brianza, M.: Organisational change and knowledge management in PLM implementation. International Journal of Product Lifecycle Management 1(1), 43-51 (2005)

[10] Cooper, R.B., Zmud, R.W.: Information Technology Implementation Research: A Technological Diffusion Approach. Management Science 36(2), 123-139 (1990)

[11] Jasperson, J., Carter, P.E., Zmud, R.W.: A comprehensive conceptualization of postadoptive behaviors associated with information technology enabled work systems. MIS Quarterly 29(3), 525-557 (2005) 
[12] Ferneley, E.H., Sobreperez, P.: Resist, comply or workaround? An examination of different facets of user engagement with information systems. European Journal of Information Systems 15(4), 345-356 (2006)

[13] Boudreau, M.-C., Robey, D.: Enacting Integrated Information Technology: A Human Agency Perspective. Organization Science 16(1), 3-18 (2005)

[14] Leonardi, P.M.: When Flexible Routines Meet Flexible Technologies: Affordance, Constraint, and the Imbrication of Human and Material Agencies. MIS Quarterly 35(1), 147-167 (2011)

[15] Hoopes, D.G., Postrel, S.: Shared knowledge, "glitches," and product development performance. Strategic Management Journal 20(9), 837-865 (1999)

[16] Patnayakuni, R., Ruppel, C.P., Rai, A.: Managing the Complementarity of Knowledge Integration and Process Formalization for Systems Development Performance. Journal of the Association for Information Systems 7(8), 545-567 (2006)

[17] Grieves, M.: Product lifecycle management: driving the next generation of lean thinking. McGraw-Hill, New York (2006)

[18] Walsh, J.P., Ungson, G.R.: Organizational Memory. Academy of Management Review 16(1), 57-91 (1991) 